\title{
Psychometric properties of the revised conscientiousness dimension of Inventário Dimensional Clínico da Personalidade (IDCP)
}

\author{
Propriedades psicométricas da versão revisada da dimensão conscienciosidade \\ do Inventário Dimensional Clínico da Personalidade (IDCP)
}

Lucas de Francisco Carvalho, ${ }^{1}$ Bruna Daniela Balbino de Souza, ${ }^{2}$ Ricardo Primi ${ }^{1}$

\begin{abstract}
This study investigated the psychometric properties of the revised scale of conscientiousness of a clinical personality inventory (Inventário Dimensional Clínico da Personalidade, IDCP). One hundred and twenty participants (68 women; $56.7 \%$ ) aged 18 to 53 years $($ mean $=22.58$, standard deviation $=$ 6.19) were recruited by convenience and answered the IDCP and the NEO Personality Inventory - Revised. The analysis of internal structure, association with external variables and reliability of the dimension under review confirmed its validity. The psychometric characteristics of the revised dimension seem to be more adequate than those of the original version and more focused on pathological functioning, which was expected and desirable.
\end{abstract}

Keywords: Psychiatric disorders, DSM-IV-TR, psychopathology.

\section{Resumo}

O presente estudo teve como objetivo investigar as propriedades psicométricas da versão revisada da dimensão conscienciosidade do Inventário Dimensional Clínico da Personalidade (IDCP). Para tanto, participaram da pesquisa 120 sujeitos, recrutados por conveniência, com idade variando entre 18 e 53 anos (média = 22,58; desvio padrão $=6,19)$, sendo 68 mulheres $(56,7 \%)$. Todos os sujeitos responderam o IDCP e o Inventário de Personalidade NEO-PI Revisado. Os dados encontrados no estudo foram favoráveis quanto às evidências de validade com base na estrutura interna e na relação com variáveis externas, bem como em relação à fidedignidade da dimensão revisada do instrumento. A partir disso, aponta-se que a dimensão revisada é mais adequada do ponto de vista psicométrico quando comparada com a versão original da mesma e, além disso, apresenta conteúdos mais voltados para o funcionamento patológico, o que era esperado e desejável.

Descritores: Transtornos psiquiátricos, DSM-IV-TR, psicopatologia.

\footnotetext{
${ }^{1}$ Universidade São Francisco (USF), Itatiba, SP, Brazil. ${ }^{2}$ Universidade Presbiteriana Mackenzie, São Paulo, SP, Brazil.

Financial support: Fundação de Amparo à Pesquisa do Estado de São Paulo (FAPESP), Conselho Nacional de Desenvolvimento Científico e Tecnológico (CNPq). Submitted Jun 18 2013, accepted for publication Oct 08 2013. No conflicts of interest declared concerning the publication of this article.

Suggested citation: Carvalho LF, Souza BDB, Primi R. Psychometric properties of the revised conscientiousness dimension of Inventário Dimensional Clínico da Personalidade (IDCP). Trends Psychiatry Psychother. 2014;36(1):23-31. http://dx.doi.org/10.1590/2237-6089-2013-0024
} 


\section{Introduction}

Personality is currently defined as a pattern of characteristics associated with each other and observed in the same individual. These characteristics, usually unconscious and quasi-automatic, are observed in the typical environments of certain organisms. Personality may also be defined as a set of psychological characteristics that help an individual to deal with the demands of everyday life. ${ }^{1}$ Therefore, personality functioning may be more or less adequate, in the sense that the strategies used by an individual to cope with everyday obstacles may be successful, which is the healthy expression of personality, or maladaptive, which may lead to serious difficulties in everyday life and define a pathological personality pattern. Personality disorders may be diagnosed when the functioning of an individual's personality leads to difficulties in everyday life.

Personality disorders are theoretical constructs that underlie several maladaptive styles or patterns of personality functioning in an individual's environment. According to Skodol et al., ${ }^{2}$ a person should be diagnosed with a personality disorder when having relevant impairments in personal (identity and selfdirectedness dimensions) and interpersonal (empathy and intimacy dimensions) functioning. In some patients, this functioning is pervasive, that is, present along the whole life and leading to important recurrent difficulties in different areas.

In the attempt to understand such functioning, several theoretical models have been described in the scientific literature. One of them is the theory of personality styles, developed by Theodore Millon, who also developed the instruments derived from it to evaluate personality and personality disorders. ${ }^{1,3}$ Based on that theory, on evolutionary principles and on the categories described in the Diagnostic and Statistical Manual of Mental Disorders ${ }^{4}$ (DSM-IV-TR) Axis II, Millon defined 15 pathological personality styles, which represent nomothetic prototypes and are subdivided into different idiographic subtypes. ${ }^{1,3,5-8}$ According to Millon's model, the styles/prototypes are: schizoid, avoidant, depressive, dependent, histrionic, narcissistic, antisocial, sadistic, compulsive, negativist, masochist, paranoid, schizotypal, borderline and hypomanic. However, to this date the instruments developed according to Millon's model have not accounted for such functioning, described only in the author's latest publications. ${ }^{3}$

Based on Millon's model and the DSM-IV-TR Axis $\mathrm{II}^{4}$ and empirically derived from a dimensional model, ${ }^{9}$ Carvalho \& Primi developed a clinical inventory of personality dimensions, the Inventário Dimensional Clínico da Personalidade (IDCP) (Carvalho LF, Primi R,
Inventário Dimensional Clínico da Personalidade, personal communication, 2011). ${ }^{10}$ This self-report instrument to evaluate pathological aspects of personality comprises 163 items in 12 dimensions: dependency, aggressiveness, mood instability, eccentricity, need for attention, suspiciousness, grandiosity, detachment, avoidance of criticism, self-sacrifice, conscientiousness and impulsivity. Each of these dimensions is closely associated with the pathological personality styles described by Millon. ${ }^{10}$

Carvalho ${ }^{10}$ evaluated the psychometric properties of the IDCP dimensions and confirmed their adequacy based on reliability indices and validity evidence of its internal structure (Classical Test Theory and Item Response Theory), as well as on external variables and criteria. The inventory was applied to 1,281 people: 1,154 without any known psychiatric diagnosis and 127 with a diagnosis of a psychiatric disorder. Their ages ranged from 18 to 90 years (mean $[\mathrm{M}]=26.64$; standard deviation $[S D]=8.94)$, and $61.8 \%$ were women. Exploratory factor analysis and reliability coefficients (Cronbach alpha) revealed that the dimensions were interpretable according to the theory adopted, and the internal consistency indices were satisfactory for the eleven dimensions of the instrument, at a cut-off point of 0.70 .

The Rasch model was also used to evaluate the internal structure of IDCP dimensions. ${ }^{10}$ The association between dimensions, the analysis of the response categories, goodness-of-fit indices and reliability coefficients found in the study confirmed the adequacy of the internal structure previously evaluated using the Classical Test Theory. Specifically, results confirmed that: IDCP factors are unidimensional; respondents used all response categories according to category grading; mean values of goodness-of-fit indices met the cut-off point used in the study; and overall reliability indices were greater than 0.70 .

The same study found evidence of validity in the association with other variables, such as the dimensions and facets of the revised NEO Personality Inventory (NEO-PI-R) and psychiatric diagnoses. In general, findings confirmed all the associations previously expected between the IDCP dimensions and the NEO-PI-R dimensions and facets, as well as the associations with the different DSM-IV-TR Axis II psychiatric diagnoses. ${ }^{4}$ Overall, data suggested that the IDCP might be useful to evaluate pathological personality traits. However, the author also made some recommendations about instrument adjustments. ${ }^{10}$ Of all recommendations, the dimension of conscientiousness, associated with diagnostic criteria typical of obsessive-compulsive personalities, had the most aspects to be revised. The items in this dimension refer to the need to do things in the most organized and ordered way possible and to be 
responsible and focused on obligations, the presence of excessive concerns, self-oriented perfectionism, rigid rules for relationships, and a focus on obligations and work. Basically, the aspects to be revised were those associated with its reliability coefficient $(\alpha=0.69)$, as it was the only IDCP dimension with a coefficient below 0.70 , and the representativeness of the construct under evaluation, because there was evidence that suggested that the IDCP dimension of conscientiousness might tend to evaluate healthy characteristics, rather than pathological traits.

Based on the data found in that study and the importance of ensuring that all IDCP dimensions primarily evaluate pathological personality characteristics, the same group of authors has evaluated the conscientiousness dimension by reviewing the literature in search of characteristics clearly associated with conscientiousness, as well as traits associated with components of the obsessive-compulsive personality (Carvalho LF, Balbino BD, Primi R, Revisão da dimensão conscienciosidade do Inventário Dimensional Clínico da Personalidade - IDCP, 2013, personal communication/ submitted article). That study was divided into six independent phases, briefly described below.

In the first phase, the literature was reviewed to define aspects typically associated with the dimensions that evaluate the pathological characteristics of obsessive-compulsive personality disorders. In this phase, the authors used the Diagnostic and Statistics Manual of Mental Disorders (DSM-5), ${ }^{11}$ the Personality Inventory for DSM- $5^{12}$ (PID-5), the Shedler-Westen Assessment Procedure (SWAP) ${ }^{13}$ and the study conducted by Clark $^{14}$ because of the importance of these models in the literature. In the second phase, the characteristics associated with the dimension of conscientiousness in the IDCP were selected based on the literature reviewed. The constructs were organized in the third phase, when items were developed for all the characteristics found in the database. These items were based on 12 constructs: DSM 5 - identity (self), self-directedness (self), empathy (interpersonal) and intimacy (interpersonal); PID-5 - perseveration and rigid perfectionism; SWAP - obsessionality; and, from the study by Clark - grandiosity/egocentricity, emotional detachment, rigidity, self-centeredness/exploitation and passive-aggressiveness. In the next phase, the most adequate items were selected. The authors independently selected the items that they considered to be more adequate, and a consensus was reached about what items should be included. In the fifth phase, the authors evaluated the representativeness of the 11 items of the conscientiousness dimension when compared with the items created during the study; that is, the original items and those developed during the study were divided into groups and co the specific conscientiousness contents under evaluation were compared. Results showed how much the earlier items already approached the contents of new items. After that, the authors excluded the items with contents already included in the original items. The sixth phase was the final selection of new items for the revised version of the conscientiousness dimension, as well as the final review of the items selected along all study phases, particularly during phase 5 . The new conscientiousness dimension comprised 34 new items and 11 items from the original version of this dimension.

Although the IDCP has adequate psychometric properties, all its dimensions are currently under revision for improvements. Our study evaluated the psychometric properties of the revised version of the IDCP conscientiousness dimension. For that purpose, validity evidence was analyzed based on internal structure and the association with external variables and reliability coefficients (internal consistency) of the dimension under review.

The external variables were the dimensions of neuroticism, extraversion, agreeableness, openness to experience and conscientiousness, as well as the facets of neuroticism and conscientiousness of the NEO-PI-R. ${ }^{15}$ This instrument was selected due to its nature (selfreport), the large number of studies about it and the empirical soundness of its underlying model (five broad factors). Moreover, there are consistent findings reported in the literature about the measurement of pathological personality characteristics using the NEO-PI-R, although some difficulties have also been reported. ${ }^{16-19}$ The detailed discussion of such difficulties is out of the scope of our study, but some data suggest that the NEO-PI-R has limitations as an instrument to evaluate pathological personality characteristics, particularly those associated with certain dimensions and facets.

\section{Method}

\section{Participants}

One hundred and twenty participants aged 18 to 53 years ( $M=22.58 ; S D=6.19$ ) ( 68 women, $56.7 \%$ ) were recruited by convenience. Fourteen had not completed high school, and the others $(n=106)$ had not finished college. Most $(n=116)$ reported not being under psychiatric treatment and not taking any psychotropic medication, and 101 reported not undergoing any psychological treatment.

\section{Instruments}

The IDCP was developed on the basis of the theory of Millon and the diagnostic categories of the DSM- 
IV-TR Axis II. ${ }^{4}$ To evaluate pathological personality characteristics, it has 163 items in 12 dimensions: dependence - incapacity to make decisions and feelings that one' own performance is inadequate; aggressiveness - violent disrespect to others and violent acts; mood instability - mood variation with irritability, sadness and guilt; eccentricity - eccentric behaviors, feelings of being different and lack of pleasure in being with other people; need for attention - friendship seeking, seduction and exaggerated need for attention from others; diffidence - incapacity to trust people and ideas of persecution; grandiosity - exaggerated need for recognition and admiration, exaggerated belief in one's own merit and superiority; indifference - preference for being alone and little or no pleasure in relationships; criticism avoidance - humiliation, belief in one's own incapacity and fear of criticism from others; self-sacrifice - self-disrespect, helping others despite harm to self; conscientiousness - need for organization and order, perfectionism, rigidity and extreme preoccupation; and impulsiveness - inconsequence, breaking laws and engaging in dangerous activities.

The items were answered using a 4-point Likertlike scale that ranged from "does not describe me at all" (1) to "describes me accurately" (4). According to Carvalho, ${ }^{10}$ most dimensional psychometric properties, validity evidence and reliability coefficients were good. Mean application time was 20 minutes.

The Brazilian version of the NEO-PI- $\mathrm{R}^{15}$ is a selfreport test for the psychological evaluation of personality in all facets of five dimensions: neuroticism, openness to experiences, agreeableness, conscientiousness and extraversion. A 5-point Likert-like scale is used to answer each item of this inventory, and scores range from 1 - "I completely disagree" to 5 - "I completely agree." Mean time for the application of this instrument is about 25 minutes. Studies of validity and reliability described in the test manual confirm the adequacy of the Brazilian version of this instrument.

\section{Procedures and data analysis}

This study was approved by the Review Board of the institution where it was conducted. After approval, participants were recruited in classrooms or on the campus of private universities of the city of São Paulo. Individuals were invited to participate in the study and were given the text of an informed consent term. The participants were only included in the study after reading and signing the consent term. During data collection, at least one of the authors was present to clarify any questions that the participants might have.

After collection, data were distributed in tables and analyzed statistically. Because of the objectives of this study and the preparation for exploratory factor analysis, parallel analysis was first used to make a decision about the number of factors to be retained. ${ }^{20,21}$ The software R 2.15.3 was chosen because it performs parallel analysis of variables for polychoric correlations, which was the case in this study. A database was created using the software MPlus 6.12 for the exploratory factor analysis with the variables for the polychoric correlations, and for the determination of coefficients to confirm the fit of the structure for the study sample. The goodness-of-fit values of these indices were also indicative of sample fit. The resulting data were compared with those found by Carvalho. ${ }^{10}$ Finally, the factors found, understood as dimensions of a broader latent construct (conscientiousness), were correlated with the facets of only two dimensions of the NEOPI-R: of the conscientiousness dimension, because of their close association with the latent construct of the dimension under focus; and of the neuroticism dimension, because of their close association with pathological personality characteristics.

\section{Results and discussion}

The parallel analysis to polychoric variables resulted in up to six factors with large eigenvalues not randomly generated. After that, the MPlus software performed exploratory factor analysis using geomin, a type of oblique rotation, and constraining it to six factors. First, the indices of goodness-of-fit generated during calculations were analyzed: $\chi^{2} / \mathrm{df}=1.13$; root mean square error of approximation (RMSEA) = 0.033; comparative fit index $(\mathrm{CFI})=0.948$; and standardized root mean residual $(\mathrm{SMR})=0.066$. According to the cutoff points adopted, ${ }^{22}$ the indices indicated good $\left(\chi^{2} / \mathrm{df}\right.$, RMSEA and SMR) or fair (CFI) fit. The resulting indices, according to this study sample, demonstrated that the six-factor structure should be maintained.

Factor loadings, number of items per factor and internal consistency indices (Cronbach alpha) are shown in Table 1 . The numbers in bold correspond to items maintained in each facet.

Some of the items that had a large factor loading in each facet were not kept, and, therefore, are not in bold in Table 1. There was an explicit attempt to keep small groups of items in the facets of the IDCP dimensions, because, otherwise, the groups of facets would be excessively large and make the use of the IDCP impractical for clinical routine. Three criteria were used to exclude items: a) the item decreased or did not increase the values of internal consistency of the facet; b) interpretive consistency was too low to maintain the item in the facet; c) there were greater factor loadings in 
Table 1 - Exploratory factor analysis and internal consistency indices

\begin{tabular}{|c|c|c|c|c|c|c|}
\hline Item & $\begin{array}{l}\text { Need for } \\
\text { routine }\end{array}$ & $\begin{array}{l}\text { Preoccupation with } \\
\text { details }\end{array}$ & Meticulousness & $\begin{array}{c}\text { Over-devotion to } \\
\text { work }\end{array}$ & $\begin{array}{l}\text { Self-oriented } \\
\text { perfectionism }\end{array}$ & $\begin{array}{l}\text { Emotional } \\
\text { constriction }\end{array}$ \\
\hline 1 & 0.141 & 0.092 & 0.019 & 0.165 & -0.035 & 0.460 \\
\hline 2 & 0.046 & 0.233 & 0.103 & 0.443 & 0.243 & 0.019 \\
\hline 3 & -0.005 & 0.236 & -0.021 & 0.701 & -0.038 & -0.012 \\
\hline 4 & 0.066 & 0.469 & 0.576 & -0.048 & 0.031 & -0.157 \\
\hline 5 & 0.017 & 0.048 & -0.156 & 0.695 & 0.242 & 0.109 \\
\hline 6 & -0.060 & 0.529 & -0.162 & 0.083 & -0.113 & -0.005 \\
\hline 7 & 0.008 & 0.369 & 0.101 & -0.112 & 0.290 & 0.073 \\
\hline 8 & -0.071 & 0.259 & 0.665 & 0.056 & 0.089 & -0.040 \\
\hline 9 & -0.080 & -0.022 & 0.135 & 0.401 & -0.018 & 0.578 \\
\hline 10 & 0.090 & 0.043 & 0.624 & 0.061 & -0.346 & -0.008 \\
\hline 11 & 0.018 & 0.279 & 0.011 & 0.463 & 0.067 & 0.037 \\
\hline 12 & -0.021 & 0.209 & -0.117 & 0.027 & 0.003 & 0.113 \\
\hline 13 & 0.089 & 0.188 & 0.011 & 0.028 & 0.109 & 0.191 \\
\hline 14 & 0.028 & 0.519 & -0.100 & -0.001 & 0.307 & -0.086 \\
\hline 15 & 0.082 & 0.009 & 0.503 & -0.239 & -0.156 & 0.194 \\
\hline 16 & 0.004 & 0.106 & 0.633 & 0.331 & -0.111 & -0.114 \\
\hline 17 & 0.110 & -0.013 & 0.128 & 0.301 & 0.566 & 0.003 \\
\hline 18 & -0.144 & 0.247 & 0.442 & 0.188 & 0.082 & 0.023 \\
\hline 19 & 0.055 & 0.075 & -0.223 & 0.319 & 0.341 & 0.235 \\
\hline 20 & 0.010 & 0.291 & 0.350 & 0.357 & -0.028 & -0.023 \\
\hline 21 & 0.019 & -0.062 & 0.458 & 0.485 & -0.311 & 0.191 \\
\hline 22 & 0.029 & 0.238 & 0.573 & -0.027 & 0.199 & 0.043 \\
\hline 23 & -0.042 & 0.039 & 0.190 & 0.185 & -0.011 & 0.408 \\
\hline 24 & 0.017 & -0.072 & -0.003 & 0.519 & 0.325 & 0.055 \\
\hline 25 & -0.124 & 0.182 & 0.044 & 0.283 & 0.450 & -0.067 \\
\hline 26 & 0.093 & 0.021 & 0.004 & 0.343 & -0.033 & 0.401 \\
\hline 27 & 0.024 & 0.481 & 0.505 & 0.004 & 0.039 & 0.026 \\
\hline 28 & -0.045 & -0.032 & 0.666 & 0.017 & 0.120 & 0.308 \\
\hline 29 & 0.118 & 0.526 & -0.129 & 0.022 & -0.020 & 0.194 \\
\hline 30 & 0.669 & -0.136 & 0.053 & 0.304 & 0.177 & -0.020 \\
\hline 31 & 0.124 & 0.358 & 0.000 & 0.339 & 0.099 & -0.113 \\
\hline 32 & 0.335 & 0.094 & -0.115 & 0.026 & 0.250 & 0.420 \\
\hline 33 & 0.695 & 0.045 & 0.076 & 0.031 & -0.114 & 0.012 \\
\hline 34 & 0.135 & 0.115 & 0.389 & -0.003 & 0.499 & -0.125 \\
\hline 35 & 0.305 & -0.040 & -0.078 & 0.292 & 0.080 & 0.396 \\
\hline 36 & -0.060 & 0.877 & 0.034 & 0.068 & -0.002 & 0.095 \\
\hline 37 & 0.027 & 0.741 & 0.081 & -0.200 & 0.005 & 0.301 \\
\hline 38 & -0.097 & -0.060 & 0.044 & 0.116 & 0.635 & 0.203 \\
\hline 39 & -0.078 & 0.331 & 0.095 & 0.139 & -0.030 & -0.298 \\
\hline 40 & -0.006 & -0.100 & 0.603 & -0.003 & 0.353 & 0.270 \\
\hline 41 & -0.113 & 0.608 & 0.018 & -0.030 & -0.153 & 0.329 \\
\hline 42 & 0.289 & 0.296 & 0.072 & 0.304 & -0.020 & -0.181 \\
\hline 43 & 0.372 & 0.047 & -0.006 & -0.108 & 0.281 & 0.288 \\
\hline 44 & 0.372 & 0.450 & -0.106 & 0.102 & 0.120 & -0.121 \\
\hline 45 & 0.858 & -0.009 & 0.165 & -0.019 & -0.085 & 0.101 \\
\hline$\alpha$ & 0.76 & 0.73 & 0.77 & 0.69 & 0.61 & 0.70 \\
\hline No. of items & 3 & 3 & 3 & 4 & 4 & 5 \\
\hline
\end{tabular}


other items. After that, 22 items ( 3 to 5 items per facet) were kept in the revised version of the conscientiousness dimension. The internal consistency indices of the factors ranged from 0.61 to 0.77 , and the dimension as a whole had an index of 0.84 , which may be classified as good because of the small number of items per facet. ${ }^{23,24}$

=Below we describe the facets found, including the name assigned to each one according to the content of the set of items. The names were chosen by the authors according to item contents and to the terms typically adopted in the literature.

The first facet, need for routine, has items to assess the difficulty in dealing with changes in everyday life and in performing tasks (example: "I always do things in the same way, even when this may result in some harm to $\left.\mathrm{me}^{\prime \prime}\right)$. The second, called preoccupation with details, refers to important and evident preoccupation with details that, in general, are not perceived by most people (example: "People do not usually notice small details, but I pay a lot of attention to them"). Meticulousness is the third facet; it includes items that refer to the need to always perform tasks to perfection (example: "Tasks should always be performed to perfection"). The fourth facet, named over-devotion to work, refers to people that are interpersonally rigid and highly focused on their work (example: "No relationship is more important than my work"). The next facet, self-oriented perfectionism, deals with the need for perfection with a focus on self as the vehicle to achieve such perfection, resulting in interpersonal losses (example: "I often miss events because I have to finish something that is almost perfect"). The sixth, and last, facet, constriction, refers to interpersonal, emotional and financial restraint and formality (example: "I'm an extremely reserved person and avoid sharing my feelings") Table 2 shows each of the facets found and the theories adopted to revise the conscientiousness dimension.

All theories were more or less represented in the revised dimension. For example, the obsessionality factor, extracted from the model used as a basis for the
Table 2 - Association between facet contents and the theoretical bases used in the revision of the dimension

\begin{tabular}{|c|c|c|c|c|}
\hline Facets & DSM-5 & PID-5 & SWAP & Clark \\
\hline Need for routine & & & & \\
\hline Preoccupation with details & & & & \\
\hline Meticulousness & & & & \\
\hline Over-devotion to work & & & & \\
\hline Self-oriented perfectionism & & & & \\
\hline Emotional constriction & & & & \\
\hline
\end{tabular}

SWAP, ${ }^{13}$ underlies most of the facets found in this study. Obsessionality in SWAP is described as an exaggerated concern with rules and organization; absorption in details; adherence to daily routines; preoccupation with dirt/cleanliness; being stingy and withholding; thinking in intellectualized terms; hoarding, accumulating even worthless things; having excessive devotion to work. This is associated with the items in the dimension of conscientiousness, whose contents are clearly heterogeneous. In contrast, the facets in the PID $-5^{12}$ are specifically focused on two factors.

Table 3 shows the correlation of facets found in this study and the total score of the new dimension.

The coefficient of correlation between total score and the facets ranged from 0.58 to 0.73 , which demonstrated the great consistency of the revised conscientiousness dimension, as well as a balance between the various factors evaluated in this broad dimension.

Table 4 shows the correlation between the facets of the new conscientiousness dimension and the dimensions of the NEO-PI-R.

In general, the facets and general score of the IDCP conscientiousness dimension had low to moderate negative correlations with the dimensions of extraversion, openness and agreeableness, some of which were significant. In neuroticism, however, most coefficients were close to zero, except for preoccupation with details, which was $0.37(p \leq 0.01)$. Despite that,

Table 3 - Correlation between facets and total score of the conscientiousness dimension

\begin{tabular}{|c|c|c|c|c|c|c|c|}
\hline & 1 & 2 & 3 & 4 & 5 & 6 & 7 \\
\hline 1 - Need for routine & 1 & 0.13 & $0.27 *$ & $0.30 *$ & $0.26 *$ & $0.34 *$ & $0.58^{*}$ \\
\hline 2 - Preoccupation with details & 0.13 & 1 & $0.36 *$ & $0.35^{*}$ & $0.26 *$ & $0.25 *$ & $0.60 *$ \\
\hline 3 - Meticulousness & $0.27 *$ & $0.36 *$ & 1 & $0.32 *$ & $0.40 *$ & $0.19^{+}$ & $0.63 *$ \\
\hline 4 - Over-devotion to work & $0.30 *$ & $0.35^{*}$ & $0.32 *$ & 1 & $0.51 *$ & $0.41 *$ & $0.73 *$ \\
\hline 5 - Self-oriented perfectionism & $0.26 *$ & $0.26 *$ & $0.40 *$ & $0.51 *$ & 1 & $0.30 *$ & $0.67 *$ \\
\hline 6 - Emotional constriction & $0.34 *$ & $0.25 *$ & $0.19^{+}$ & $0.41 *$ & $0.30 *$ & 1 & $0.69 *$ \\
\hline 7 - Total score & $0.58 *$ & $0.60 *$ & $0.63 *$ & $0.73 *$ & $0.67 *$ & $0.70 *$ & 1 \\
\hline
\end{tabular}

* Significant at $p=0.001$.

${ }^{+}$Significant at $\mathrm{p}=0.05$

28 - Trends Psychiatry Psychother. 2014;36(1) 
Table 4 - Correlations between facets and total score of the IDCP conscientiousness dimension and the NEO-PI-R dimensions

\begin{tabular}{lccccc}
\hline & Neuroticism & Extraversion & Openness & Agreeableness & Conscientiousness \\
\hline Need for routine & 0.08 & $-\mathbf{0 . 3 0 *}$ & $\mathbf{- 0 . 3 0 *}$ & -0.14 & 0.09 \\
Preoccupation with details & $0.37 *$ & -0.00 & $0.21^{+}$ & $-0.21^{+}$ & $0.28^{*}$ \\
Meticulousness & -0.11 & 0.06 & 0.07 & -0.08 & $\mathbf{0 . 6 3 *}$ \\
Over-devotion to work & 0.02 & -0.02 & -0.16 & $\mathbf{- 0 . 3 1 *}$ & 0.16 \\
Self-oriented perfectionism & 0.05 & -0.06 & -0.01 & $\mathbf{- 0 . 3 7 *}$ & 0.09 \\
Constriction & 0.11 & $\mathbf{- 0 . 4 6 *}$ & -0.08 & $-0.34 *$ & 0.09 \\
Total score & 0.14 & $-0.23^{+}$ & -0.07 & $\mathbf{- 0 . 3 8 *}$ & $0.33^{*}$ \\
\hline
\end{tabular}

IDCP = Inventário Dimensional Clínico da Personalidade; NEO-PI-R = NEO Personality Inventory - Revised.

Bold numbers are the highest coefficient for each factor.

* Significant at $p=0.001$.

+ Significant at $\mathrm{p}=0.05$.

the coefficient between total score and neuroticism was 0.14 and not significant, an increase over the findings reported by Carvalho in $2011^{10}(r=-0.01 ; p=n . s$.$) .$ Most coefficients of the NEO-PI-R conscientiousness dimension were also close to zero, except for three significant values: meticulousness $(0.63 ; p \leq 0.01)$, total score $(0.33 ; \mathrm{p} \leq 0.01)$ and preoccupation with details $(0.28 ; p \leq 0.01)$. Together, these data may indicate that the revised version of the conscientiousness dimension tends to measure more extreme levels of the construct, which define pathologies, particularly because of the negative coefficients of three facets, the positive coefficient of neuroticism and most other low coefficients of the NEO-PI-R conscientiousness dimension. Future studies should be conducted to confirm this hypothesis.

The NEO-PI-R primarily assesses healthy aspects of personality. Therefore, the revised dimension was expected to have a less significant association with the NEO-PI-R conscientiousness dimension than that found for the original dimension. The comparison of the correlation between the total score and the NEO-PI-R conscientiousness dimension $(0.33 ; p \leq 0.01)$ and the correlation found by Carvalho ${ }^{10}$ for the original version and the same NEO-PI-R factor $(0.52 ; \mathrm{p} \leq 0.01)$ revealed that the coefficients in this study were substantially lower, which suggests that there was a decrease in the variance shared by the two dimensions. In fact, according to the literature, except for neuroticism, the other NEO$\mathrm{PI}-\mathrm{R}$ dimensions tend to have a negative correlation with instruments that assess pathological characteristics. ${ }^{16-19}$ Therefore, data found in our study suggest that the items in the new dimension tend to measure pathological rather than healthy characteristics.

However, studies should further analyze the interpretation presented in the paragraph above. For example, using the Rasch model, based on the Item Response Theory, the distribution of items in the original version may be compared with the distribution of items in the new dimension, and the discrepancies in the latent construct measurements may be visualized. Moreover, despite the coherent correlations shown in Table 4, further studies should investigate possible explanations for the coefficients of the new conscientiousness dimension, which are greater than those of the NEOPI-R dimensions. One of the possible explanations for the low coefficients found in the comparison between the IDCP and the NEO-PI-R conscientiousness dimensions may be the constructs under evaluation. For example,

Table 5 - Correlations with the NEO-PI-R facets of conscientiousness

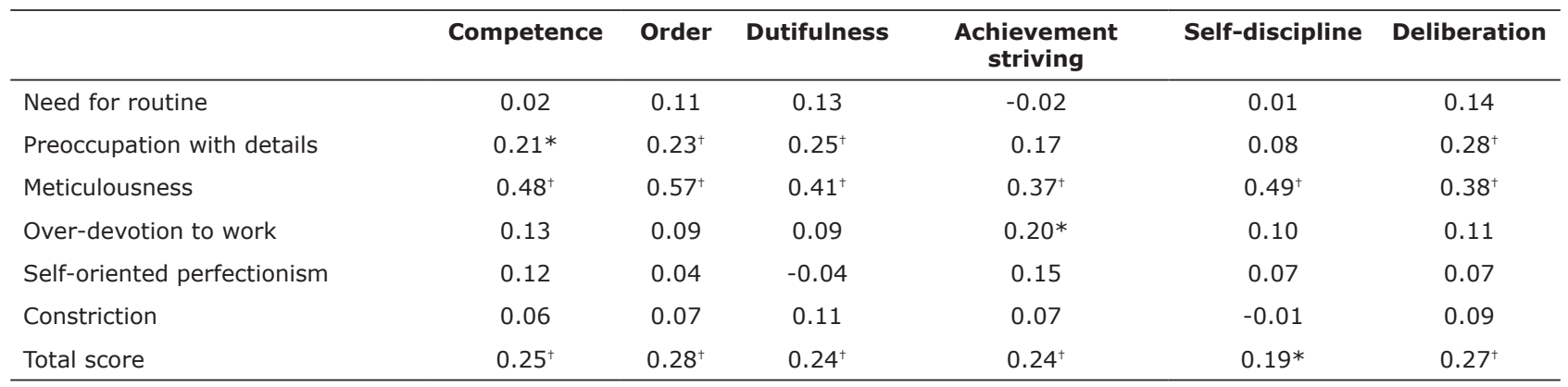

NEO-PI-R = NEO Personality Inventory - Revised.

* Significant at $\mathrm{p}=0.001$.

+ Significant at $\mathrm{p}=0.05$. 
Table 6 - Correlations with the NEO-PI-R facets of neuroticism

\begin{tabular}{|c|c|c|c|c|c|c|}
\hline & Anxiety & Angry hostility & Depression & Self-consciousness & Impulsiveness & Vulnerability \\
\hline Need for routine & 0.07 & -0.04 & 0.16 & $0.21 *$ & -0.15 & 0.07 \\
\hline Preoccupation with details & $0.38^{+}$ & $0.34^{+}$ & $0.35^{+}$ & $0.35^{+}$ & $0.21 *$ & 0.08 \\
\hline Meticulousness & -0.00 & -0.09 & -0.04 & 0.08 & -0.13 & $-0.24^{+}$ \\
\hline Over-devotion to work & -0.02 & 0.09 & 0.11 & 0.03 & -0.08 & -0.04 \\
\hline Self-oriented perfectionism & 0.08 & 0.05 & 0.12 & 0.02 & 0.04 & -0.07 \\
\hline Constriction & 0.14 & 0.16 & $0.18^{*}$ & 0.13 & -0.04 & -0.05 \\
\hline Total score & 0.17 & 0.14 & $0.23 *$ & $0.22 *$ & -0.03 & -0.06 \\
\hline
\end{tabular}

NEO-PI-R = NEO Personality Inventory - Revised

* Significant at $p=0.001$.

${ }^{+}$Significant at $p=0.05$.

data in the literature show a weak correlation $(r \leq 0.25)$ between the NEO-PI-R conscientiousness dimension and the diagnostic category of obsessive-compulsive disorders. ${ }^{25}$ Moreover, in the attempt to generate these data, we also evaluated the correlation of coefficients of the revised dimension and its facets and of the NEO-PI-R conscientiousness and neuroticism dimensions.

Table 5 shows that most coefficients were not statistically significant, and significant coefficients tended to be low. An exception to that was the coefficients found for meticulousness, which were greater than those found for the facets of order, self-discipline and competence. These data show that the NEO-PI-R conscientiousness dimension measures aspects associated with the need to perform tasks to perfection also at more extreme levels, but probably the same is not true of the other characteristics associated with conscientiousness.

According to Carvalho, ${ }^{10}$ the original version of the conscientiousness dimension had greater correlation coefficients of the facets of dutifulness and deliberation. No similar results were found in our data, that is, variance between the coefficients of the new conscientiousness dimension and the NEO-PI-R facets of the conscientiousness dimension was small (from 0.19 to $0.28 ; \mathrm{M}=0.24 ; \mathrm{SD}=0.03$ ).

Table 6 shows the correlations with the facets of neuroticism.

Most coefficients were not statistically significant, and significant coefficients ranged from 0.21 to 0.38 , that is, they tended to be low. The facet that was closest to the neuroticism facets, particularly to anxiety, angry hostility, depression and self-consciousness, was preoccupation with details. These data suggest that people that are more focused and concerned with details are also more likely to feel anxiety, hostility, depression and shyness in social situations. ${ }^{15}$ In addition, many coefficients, although low, were positive, which suggests that the variables had the same orientation and direction. These data also demonstrated that the new conscientiousness dimension tends to have items that assess more pathological content than the original dimension.

\section{Conclusion}

This study evaluated the psychometric properties of the revised version of the IDCP conscientiousness dimension. Specifically, validity evidence was found based on the internal structure and the association with external variables, and reliability indices (internal consistency) were also confirmed.

The analysis of internal structure confirmed the superiority of the revised dimension of conscientiousness because its six facets were interpretable according to the theories used as the basis of this study. Moreover, the comparison of the total score of the revised dimension and that of the original IDCP dimensions suggested that the content of the new group of items tended to be more pathological than that of the original items, which was expected and necessary. However, as mentioned above, future studies should investigate the consistency of these data. According to psychometric properties, each of the components may comprise a larger set of items than that of the group of items described. However, we attempted to reduce the number of items in each component to avoid that the instrument would become impractical for application in clinical settings because of its length.

The six facets of its internal structure had moderate to high coefficients of correlation, which suggests that, even in the case of specific conscientiousness characteristics, the latent construct is an element in common in the facets. In addition, the indices of internal consistency (Cronbach alpha) were, in general, good, particularly for the impact that the small number of items has on the formula underlying the analysis conducted in this study. Moreover, the coefficient for the new dimension ( $\alpha=$ $0.84)$ is substantially greater than that of the original set of items $(\alpha=0.69)$. 
In the analysis of validity evidence based on external criteria, the correlations with the NEO-PI-R dimensions and facets demonstrated that meticulousness was the facet with the closest association with the instrument dimensions, and most of the associations found were negative, except for the coefficients of neuroticism and conscientiousness. Moreover, most coefficients were low, which was expected because the NEO-PI-R primarily assesses healthy personality characteristics. Therefore, while the correlation coefficients between the new dimension and the NEO-PI-R dimensions and facets tended to be low to moderate, which is a positive result because the instruments measure different levels of the latent construct, the greater coefficients were expected, as in the case of conscientiousness (similar latent construct) and neuroticism (closest level to the latent construct).

However, although the set of data suggested that the new dimension actually assesses the typical pathological characteristics of the conscientiousness construct, the low correlation coefficients of some facets of the NEOPI-R dimension of conscientiousness may also be a sign of the presence of another latent construct. Future studies may rule it out after using the new dimension to assess clinical samples.

One of the limitations of this study was the number of participants in the sample, as well as their characteristics. Future studies should investigate whether the structure found in this study may be replicated using other samples, particularly with patients that have a diagnosis of personality disorder. It is also important that, once the items found in this study are replicated, the reliability indices should be analyzed for an individual's level in the latent construct, using, for example, local accuracy. ${ }^{26}$

Moreover, the contribution of this instrument to clinical practice should be evaluated considering the focus of evaluation of the IDCP and, particularly, of the dimension under analysis in this study, and of the NEO-PI-R, that is, including both more pathological and healthier characteristics. Further studies should search for evidence of the incremental validity of the IDCP and investigate whether this instrument is actually more sensitive and discriminative for clinical samples than the NEO-PI-R, developed for the population in general.

\section{References}

1. Millon T, Millon CM, Meagher S, Grossman S, Ramnath R. Personality disorders in modern life. New Jersey: Wiley; 2004.

2. Skodol AE, Clark LA, Bender DS, Krueger RF, Morey LC, Verheul $\mathrm{R}$, et al. Proposed changes in personality and personality disorder assessment and diagnosis for DSM-5 Part I: Description and rationale. Personal Disord. 2011;2:4-22.
3. Millon T. Disorders of personality: introducing a DSM/ICD spectrum from normal to abnormal. New Jersey: Wiley; 2011.

4. American Psychiatric Association. Manual Diagnóstico e Estatístico de Transtornos Mentais - $4^{a}$ edição (DSM-IV-TR). Porto Alegre: Artmed; 2003.

5. Millon T, Davis RD. Disorders of personality DSM-IV and beyond. New Jersey: Wiley; 1996.

6. Millon T, Grossman S. Moderating severe personality disorders: personalized psychotherapy approach. New Jersey: Wiley; 2007.

7. Millon T, Grossman S. Overcoming resistant personality disorders. New Jersey: Wiley; 2007.

8. Millon $\mathrm{T}$, Grossman $\mathrm{S}$, Tringone R. The Millon personality spectrometer: a tool for personality spectrum analyses, diagnoses, and treatments. In: Millon $\mathrm{T}$, Krueger RF, Simonsen $\mathrm{E}_{\text {, }}$ editors. Contemporary directions in psychopathology: scientific foundations of the DSM-V and IDC-11. New York: Guilford; 2010.

9. Schroeder ML, Wormworth JA, Livesley WJ. Dimensions of personality disorder and their relationships to the big five dimensions of personality. Psychol Assess. 1992;4:47-53.

10. Carvalho LF. Desenvolvimento e verificação das propriedades psicométricas do Inventário Dimensional Clínico da Personalidade [dissertation]. Itatiba: Universidade São Francisco; 2011.

11. American Psychiatric Association. Diagnostic and Statistical Manual of Mental Disorders (DSM-5). http://www.dsm5.org/ Pages/Default.aspx. Accessed 2013 Feb.

12. Krueger RF, Derringer J, Markon KE, Watson D, Skodol AE. Initial construction of a maladaptive personality trait model and inventory for DSM-5. Psychol Med. 2011;8:1-12.

13. Shedler J, Westen D. Dimensions of personality pathology: an alternative to the five-factor model. Am J Psychiatry 2004; 161:1743-54.

14. Clark LA. Toward a consensual set of symptom clusters for assessment of personality disorder. In: Butcher JN, Spielberger $C D$, editors. Advances in personality assessment, Lawrence Erlbaum Associates. New Jersey: Erlbaum; 1990.

15. Costa PT, McCrae RR. NEO PI-R - Inventário de personalidade NEO revisado. São Paulo: Vetor; 2009.

16. Lynam DR. Assessment of maladaptive variants of Five-Factor Model traits. J Pers. 2012;80:1593-614

17. Miller JD. Five-Factor Model personality disorder prototypes: a review of their development, validity, and comparison to alternative approaches. J Pers. 2012;80:1565-91.

18. Samuel DB, Gore WL. Maladaptive variants of conscientiousness and agreeableness. J Pers. 2012;80:1669-96.

19. Widiger TA, Costa Jr PT. Integrating normal and abnorma personality structure: the Five-Factor Model. J Pers. 2012;80:1471-506.

20. Hayton JC, Allen DG, Scarpello V. Factor retention decisions in exploratory factor analysis: a tutorial on parallel analysis. Organ Res Methods. 2004;7:191-205.

21. Watkins MW. Determining parallel analysis criteria. J Mod Appl Stat Methods. 2006;5:344-6.

22. Hooper D, Coughlan J, Mullen MR. Structural equation modelling: guidelines for determining model Fit. Electron J Bus Res Methods. 2008;6:53-60.

23. Nunnally JC. Psychometric theory. New York: McGraw-Hill; 1978.

24. Embretson SE. The new rules of measurement. Psychol Assess. 1996;8:341-9.

25. Daniel $\mathrm{MH}$. Behind the scenes: using new measurement methods on the DAS and KAIT. In: Embretson SE, Hershberger SL, editors. The new rules of measurement: what every psychologist and educator should know. New Jersey: Erlbaum; 1999.

26. Samuel DB, Widiger TA. A meta-analytic review of the relationships between the five-factor model and DSM-IV-TR personality disorders: a facet level analysis. Clin Psychol Rev. $2008 ; 28: 1326-42$

\section{Correspondence:}

Lucas de Francisco Carvalho

Universidade São Francisco

Rua Alexandre Rodrigues Barbosa, 45, Itatiba

13251-900 - São Paulo, SP - Brazil

Tel./Fax: +55 (11) 4534.8053

E-mail: lucas@labape.com.br 